\title{
Is Emergency Peripartum Hysterectomy Avoidable in the Background of its Morbidity and Mortality? A Retrospective Evaluation in a Tertiary Level Hospital
}

\author{
S. Patra ${ }^{1}$, S.Y. Siddika' , P.K. Mistri ${ }^{3}$ S. Roy ${ }^{4}$ \\ ${ }^{1}$ Department of Obstetrics and Gynaecology, Medical College Hospital, Kolkata, West Bengal, India. ${ }^{2}$ Department of \\ Obstetrics and Gynaecology, Medical College Hospital, Kolkata, West Bengal, India. ${ }^{3}$ Department of Obstetrics and \\ Gynaecology, Medical College Hospital, Kolkata, West Bengal, India. ${ }^{4}$ Department of Obstetrics and Gynaecology, \\ Medical College Hospital, Kolkata, West Bengal, India.
}

\section{ABSTRACT}

\section{BACKGROUND}

Emergency Peripartum Hysterectomy (EPH) is a life saving measure to manage the intractable haemorrhage both during and after vaginal as well as abdominal delivery. The study was conducted to assess the socio-demographic and obstetric profile of study subjects, to determine the incidence, indication, and type of EPH, including outcome of emergency peripartum hysterectomy.

\section{METHODS}

This is a retrospective study of patients who underwent emergency peripartum hysterectomy. Cases of emergency peripartum hysterectomy were performed shortly (within hours) after delivery up to 48 hours postpartum. We obtained the medical records like demographic details, previous obstetric history, details of current pregnancy, and delivery, amount of blood transfusion, and maternal outcome arising due to emergency peripartum hysterectomy.

\section{RESULTS}

During the study period, the incidence of EPH was 1.63 per 1000 deliveries. Risk factors associated with EPH were improper education of women, inadequate antenatal care, multiparty, previous $\mathrm{h} / \mathrm{o}$ caesarean section etc. The most common indications for EPH were atonic PPH (45\%), followed by rupture uterus (23.3\%), placenta previa $(18.3 \%)$ and placenta accreta (13.3\%). Subtotal hysterectomy was the method of EPH in most (55\%) of cases. The most common complications due to EPH in our study were wound sepsis, paralytic ileus, and bladder injury. Approximately $20 \%$ of the cases were sent to CCU (Critical Care Unit). Mortality among cases of EPH was 3.3\%.

\section{CONCLUSIONS}

Hence the risk factors associated with EPH are multiparity, previous h/o caesarean section, inadequate antenatal care, and improper education to the women in our society. The incidence of EPH can be reduced by improving socioeconomic status, upgradation of woman education, promotion of adequate antenatal care, improvement of services at lower tier, adoption of small family norm, proper management of labour by partograph, cardiotocography (CTG) and reduction of the primary caesarean section rate.

\section{KEY WORDS}

Atonic Postpartum Haemorrhage (Atonic PPH), Emergency Peripartum Hysterectomy (EPH), Maternal Morbidity, Maternal Mortality, Subtotal Hysterectomy
Corresponding Author: Dr. Shabana Yeasmin Siddika, Kendua Fakir Para, P. O + P. S. Suri-Dist., Birbhum-731101, West Bengal, India. E-mail: donna27887@gmail.com

\section{DOI: 10.14260/jemds/2019/738}

Financial or Other Competing Interests: None.

How to Cite This Article:

Patra S, Siddika SY, Mistri PK, et al. Is emergency peripartum hysterectomy avoidable in the background of its morbidity and mortality? a retrospective evaluation in a tertiary level hospital. J. Evolution Med. Dent. Sci. 2019;8(45): 3403-3407, DOI: 10.14260/jemds/2019/738

Submission 12-09-2019, Peer Review 23-10-2019, Acceptance 30-10-2019, Published 11-11-2019. 


\section{BACKGROUND}

Emergency peripartum hysterectomy (EPH) is a life-saving measure to manage intractable haemorrhage both during or after vaginal or abdominal delivery. In modern obstetrics, the overall incidence of EPH is $0.05 \%$, but there are considerable differences in incidence in different parts of the world, depending on modern obstetric services, standards and awareness of antenatal care, and the effectiveness of family planning activities of a given community. ${ }^{1}$

Postpartum haemorrhage $(\mathrm{PPH})$ is one of the most important indications for Emergency Peripartum Hysterectomy (EPH).2 Severe PPH continues to be the leading cause maternal deaths accounting for $27.1 \%$ of death worldwide. There has been a steady rise in incidence of PPH, in spite of there being great advances in availability of better drugs for conservative management. A meta-analysis showed that incidence of obstetric hysterectomy has been increasing at the rate of $8 \%$ annually. ${ }^{3}$ The risk factors of postpartum haemorrhage include uterine atony, abnormal placentation, precipitate or prolonged labour, bleeding due to coagulopathy, fetal macrosomia, multiparity, maternal obesity and the previous history of primary postpartum haemorrhage. In recent times, the risk factors for EPH have increased resulting from the increasing rates of caesarean deliveries. Several conservative interventional strategies include uterine massage, uterotonic drugs, uterine or hypogastric artery embolisation, haemostatic sutures, bilateral internal iliac artery ligation. ${ }^{4}$ Other indications of EPH are uterine rupture and abnormal placentation (Placenta previa/placenta accreta) with or without caesarean section. EPH appears to be increasing by $0.026 \%$ in high income countries and by $0.28 \%$ in low income countries. ${ }^{2} \mathrm{EPH}$ following vaginal delivery is constant and varies between 0.1 0.3 per 1000 deliveries. EPH following caesarean section varies widely between 0.17-8.7 per 1000 deliveries. ${ }^{3}$ The indications of EPH have changed throughout the years. Currently the increase in caesarean delivery rate and the associated risks of abnormal placentation (Placenta previa and placenta accrete) have been recognized as precipitating risk factors for EPH. ${ }^{2}$ The choice between conservative management and EPH should be individualized. In situations where conservative treatment has failed, there should be no further delay in performing EPH, as delay leads to increase in blood loss, transfusion require men, operative time, DIC and increased possibility of admission to ICU. Cases of EPH are counted under maternal near miss (MNM) census. Maternal Mortality rate for EPH varies between $1 \%$ to $6 \%$ but some studies in regions with limited medical and hospital resources indicate that rate is as high as $30 \% .5$ Total hysterectomy is the recommended method of EPH due to the potential risk of malignancy of the cervical stump and the need for regular cytology and other associated problems such as bleeding or discharge. The proponents of subtotal hysterectomy report a lesser blood loss, a reduced need for blood transfusion, reduced operative time, reduced intra and post-operative complications. Subtotal hysterectomy may not be effective in management of the accreta in lower uterus. The final decision to perform subtotal or total hysterectomy would be influenced by patient's condition. Hence, while total abdominal hysterectomy is a more convenient procedure, subtotal EPH may be a better choice in certain conditions where surgery needs to be completed in a shorter time ${ }^{4}$. The study was conducted to 1) To assess the Socio-Demographic and Obstetric profile of the study subject 2) To find out the incidence, Indications and types of Emergency Peripartum Hysterectomy, and 3) To determine the outcome of Emergency Peripartum Hysterectomy observed in our institution. Our institution, though a centrally situated tertiary care centre, it serves a vast area and also referral centre for many secondary care centers of our state. This study would help in identification of avoidable factors and stress the need to organize health care services so as to improve maternal and fetal outcome.

\section{METHODS}

A retrospective study of the patients who underwent emergency peripartum hysterectomy between February 2012 and January 2015 at the Department of Obstetrics and Gynaecology, Medical College and Hospital, Kolkata. Was conducted. Emergency peripartum hysterectomy was defined as caesarean hysterectomy or hysterectomy performed within 48 hours of vaginal/abdominal delivery. All the women who delivered in the hospital as well as who were referred from outside for obstetrical complications (For both, more than 28 weeks of gestation) who underwent EPH, were included in our study. Standard resuscitation measure was undertaken before proceeding with EPH. The Institute of Ethics Committee approved our study in Medical College Hospital, Kolkata.

\section{Inclusion Criterion}

All women who delivered in the hospital after 28 weeks of gestation between February 2012 and January 2015. Those women underwent hysterectomy for obstetric indications at the time of delivery with life-threatening conditions. The hysterectomy had to be performed shortly (within hours) after delivery to 48 hours postpartum. All women who delivered outside the hospital and were referred for obstetric complications meriting a hysterectomy and fulfilling all the above conditions were also be included in the study.

\section{Exclusion Criterion}

All women who underwent obstetric hysterectomy before 28 weeks of gestation, hysterectomy performed due to complications of MTP and all the patients underwent hysterectomy due to gynaecological reasons were excluded from our study.

Standard medical and surgical modalities to control the haemorrhage before hysterectomy had to be taken for all cases. All the cases of obstetric hysterectomy were performed by a senior gynaecologist and obstetrician holding post graduate degree. Decision for the obstetric hysterectomy were taken by the senior faculty of the gynaecology and obstetrics department. A predesigned preformed with variables including demographic details, previous obstetric history, details of the current pregnancy and delivery, indications for peripartum hysterectomy, outcomes of hysterectomy such as intra-operative and post-operative complications, blood transfusion, and maternal complications such as maternal death and serious complications were filled 
for each patient. After collecting relevant data from the operation theatre register and record section, each patient's case record was scrutinized with regard to incidence, age, parity, antenatal high-risk factors, indications, hysterectomy type, and complications, along with the ultimate maternal outcome. Data were manually tabulated; simple percentage calculations were done among various demographic and obstetric variables. Bar diagram and pie chart were drawn to depict the results.

\section{Statistical Analysis}

Data were manually tabulated; simple percentage calculations were done among various demographic and obstetric variables. Bar diagram and pie chart were drawn to depict the results. We used "Measure of frequency " (Count, percent etc.), type of descriptive tests in statistical analysis. We used contingency table and chi square statistics in case of inferential statics.

\section{RESULTS}

The study included 60 cases of EPH. Background characteristics of the study population are shown in Table 1. Among 36,768 deliveries, 60 women underwent EPH in the study period. The incidence of EPH was 1.63 per 1000 deliveries Muslim were $32(53.3 \%)$ and Hindu were 28(46.7\%). Mean age of study population was $28.26 \pm 6.18$ yrs. half of these women were resident of rural areas. Majority (51\%) were educated up to primary level. Three or less antenatal care (4 is minimum number of ANC according to Reproductive and child health program of India) were given to $27(45 \%)$ patients, while 33 $(55 \%)$ patients have more than equal to 4 antenatal check-ups.

Distribution of subjects according to their obstetric variables has been depicted in table 2 . Higher parity increases risk of EPH. In our study, $55 \%$ women had parity 2 or more. Previous vaginal delivery was present in $38(63.3 \%)$ women and $22(36.6 \%)$ had past h/o LSCS. Among women who were undergone EPH, 45 (75\%) women had no h/o miscarriage, 11 $(18.3 \%)$ women had single miscarriage and 4 (6.6\%) women had $\geq 2$ miscarriage. Among total EPH patients, the mode of delivery in present pregnancy were $34(56.6 \%)$ vaginal delivery, $17(28.3 \%)$ were LSCS and $9(15 \%)$ women are subjected to EPH due to rupture uterus with fetus in situ. Regarding the cause of referral for emergency peripartum hysterectomy( $\mathrm{EPH}$ ), twenty five $(41.6 \%)$ were postpartum haemorrhage (PPH), $13(21.6 \%)$ were rupture uterus, $11(18.3 \%)$ were placenta previa, $2(3.3 \%)$ cases were retained placenta, 4 (6.6\%) cases were miscellaneous i.e. post CS in labour, repeat CS in labour etc. and 5 (8.3\%) cases were admitted from OPD (Fig. 1).

Among 60 patients the indication of EPH are 27 (45\%) atonic uterus, $14(23.3 \%)$ rupture uterus, $11(18.3 \%)$ placenta previa, and 8(13. 3\%) placenta accreta. (Fig. 2). Total Abdominal Hysterectomy were 27 (45\%) and Subtotal Hysterectomy were 33(55\%). Almost all the patients had received an average of two units of blood transfusion intraoperatively and postoperatively. Only $2(3.33 \%)$ cases were complicated with bladder injury, $4(6.66 \%)$ cases had wound sepsis and $3(5 \%)$ cases had paralytic ileus. Among 60 cases undergoing EPH, 12 (20\%) cases were sent to CCU postoperatively and $2(3.33 \%)$ cases were died. Mortality among the cases of EPH was $3.33 \%$.

\begin{tabular}{|c|c|}
\hline Variables & Frequency \% \\
\hline \multicolumn{2}{|l|}{ Religion } \\
\hline Hindu & $32(53.3 \%)$ \\
\hline Muslim & $28(46.7 \%)$ \\
\hline \multicolumn{2}{|l|}{ Residence } \\
\hline Rural & $30(50 \%)$ \\
\hline Urban & $30(50 \%)$ \\
\hline \multicolumn{2}{|l|}{ Age Group } \\
\hline$\leq 25$ Years & $20(33.3 \%)$ \\
\hline $26-35$ & $32(53.3 \%)$ \\
\hline $36-45$ & $8(13.3 \%)$ \\
\hline Education-illiterate \& < primary & $6(10 \%)$ \\
\hline Primary and Middle & $28(46.7 \%)$ \\
\hline Secondary and Above & $26(43.3 \%)$ \\
\hline Utilization of ANC-0-3 Times & $27(45 \%)$ \\
\hline$\geq 4$ Times & $33(55 \%)$ \\
\hline \multicolumn{2}{|c|}{ Table 1. Background Characteristics of Study Population $(N=60)$} \\
\hline \multicolumn{2}{|c|}{$\begin{array}{l}<\text { Primary-up to } 4^{\text {th }} \text { standard, Primary and Middle below } 10^{\text {th }} \text { standard, secondary } \\
\text { and above }-10^{\text {th }} \text { standard and above. }\end{array}$} \\
\hline
\end{tabular}

\begin{tabular}{|c|c|}
\hline Variables & Frequency \\
\hline $\begin{array}{c}\text { Parity - P } 0 \\
\text { P } 1 \\
\text { P } \geq 2\end{array}$ & $\begin{array}{c}4(6.6 \%) \\
23(38.3 \%) \\
33(55 \%) \mathrm{P}<0.0001\end{array}$ \\
\hline Previous history of vaginal delivery $0-12-34-5$ & $\begin{array}{c}11(18.3 \%) \\
23(38.3 \%) \\
4(6.6 \%)\end{array}$ \\
\hline $\begin{array}{c}\text { Previous history of LSCS - No LSCS } \\
1 \text { LSCS } \\
\geq 2 \text { LSCS } \\
\end{array}$ & $\begin{array}{c}38(63.3 \%) \\
17(28.3 \%) \\
5(8.3 \%) \\
\end{array}$ \\
\hline $\begin{array}{c}\text { Previous history of miscarriage - No miscarriage } \\
1 \text { miscarriage } \\
\geq 2 \text { miscarriage }\end{array}$ & $\begin{array}{c}45(75 \%) \\
11(18.3 \%) \\
4(6.6 \%)\end{array}$ \\
\hline $\begin{array}{c}\text { Route of delivery in present pregnancy- ( outside and } \\
\text { Institutional) } \\
\text { Vaginal Delivery } \\
\text { Emergency LSCS } \\
\text { EPH in Rupture uterus with fetus in situ }\end{array}$ & $\begin{array}{c}34(56.6 \%) \\
17(28.3 \%) \\
9(15 \%)\end{array}$ \\
\hline $\begin{array}{c}\text { Type of operation during EPH- Total Abdominal } \\
\text { Hysterectomy- } \\
\text { Sub-Total Abdominal Hysterectomy- } \\
\end{array}$ & $\begin{array}{l}27(45 \%) \\
33(55 \%)\end{array}$ \\
\hline $\begin{array}{r}\text { Table 2. Obstetric Distribution of the Subj } \\
\text { Obstetric Variables }(N=60\end{array}$ & rding to \\
\hline
\end{tabular}
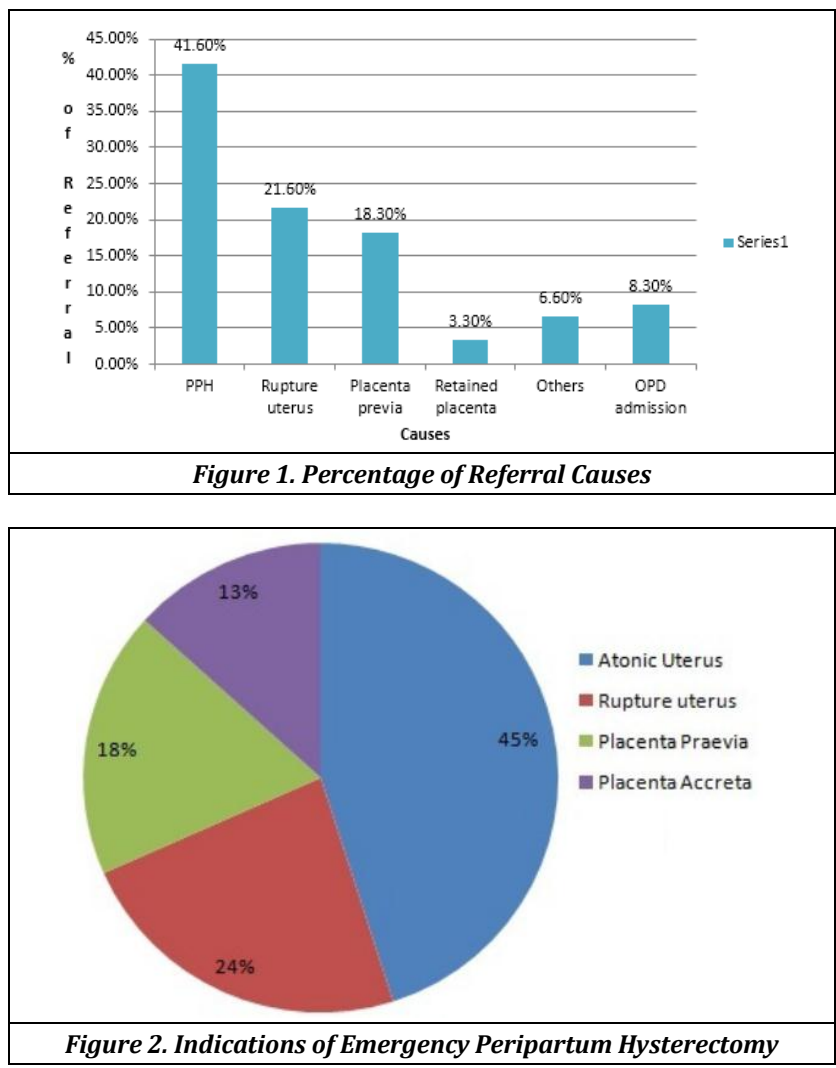


\section{DISCUSSION}

Incidence of EPH in our study was 1.63 per 1000 deliveries, which compared favourably with the previous studies. The reported incidence of EPH varied from 0.24 to 8.9 per 1000 women deliveries, ranging from 0.33 (Netherland), 0.2 (Norway), 0.3 (Ireland), 0.5 (Israel), 0.63(Saudi Arabia) and 1.2 to 2.7 per 1000 deliveries in USA $^{6}$. In our study mean maternal age was $28.26 \pm 6.18$ years. Majority of the women were 26-35 years age group consistent with the study of Ghana ${ }^{7}$. In our study majority of patients were multiparous (55\%), followed by primiparous (38.4\%), only 4 nulliparous women out of $60(6.6 \%)$ underwent emergency peripartum hysterectomy due to intractable postpartum haemorrhage not responding to conservative treatment. In the present study, $55 \%$ of the patients received minimum antenatal care according to RCH guideline, while $45 \%$ patients had no minimum antenatal care- adequate minimum antenatal care is related with the level of education. In our study $\leq 56.7 \%$ women were either illiterate or having less than equal to primary level of education which could explain the inadequacy of minimum antenatal care. Regarding the past history of mode of delivery, $63.3 \%$ women had vaginal delivery, while $36.7 \%$ women had lower segment caesarean section- exactly corroborated with the indication of EPH as major indication were uterine atony and rupture uterus rather than placenta previa or placenta accrete Mode of delivery in present pregnancy were $56.7 \%$ vaginal delivery, 28.3\% LSCS indicated indirectly the lower rate of LSCS rather than vaginal delivery over the study period in eastern India. The most frequent indication for emergency peripartum hysterectomy in the present study was uterine atony $(45 \%)$, followed by rupture uterus $(23.3 \%)$, placenta previa $(18.4 \%)$ and placenta accreta (13.3\%). Traditionally uterine atony was the most common indication for emergency peripartum hysterectomy. ${ }^{8}$ Major indication of emergency peripartum hysterectomy in the present study was similar with the Portugal study 7 . Similar results of our study had been described by Ozden et al and that was also explained by lowest rate of caesarean delivery. ${ }^{(8,9)}$ From all these dates we can say that the indication of EPH varies worldwide with mode of obstetric practice in each institution. Our study was also similar to the study by Nasrat and colleagues which had showed atonic postpartum haemorrhage followed by rupture uterus were the most common indication. ${ }^{(5,10)}$ Similarly, even in a small study of 17 patients in Saudi Arabia and 54 patients in Republic Korea, uterine atony was the most common cause $\cdot(11,12,13)$ Alka Singh et al study ${ }^{14}$ showed the similar type of result as in our study where uterine atony was the leading indication of EPH followed by rupture uterus and morbid adherent placenta. In our study subtotal hysterectomy is the most commonly performed emergency peripartum hysterectomy. Our study is exactly matched with Nigeria study ${ }^{14}$ outhern Nigeria study. ${ }^{16}$ Currently, the proportion of subtotal hysterectomy performed for emergency peripartum hysterectomy ranges from $53 \%$ to $80 \% \cdot(6,16,17)$ The complication rate for EPH were bladder injury (3.3\%) similar to the studies. Wound sepsis was slightly higher than other studies. Our study showed $20 \%$ of patients were sent to CCU higher than other studies. In our study 3.3\% died after EPHsame with the other study which had showed maternal mortality rate ranging from 0 to $12.5 \%$ with a mean of $4.8 \%$.
However, in recent times given the high rate of CS, uterine atony has been replaced by abnormal placentation, as the leading cause of EPH. The risk factors for abnormal placental invasion are placenta previa, previous uterine surgery and curettage. It is well established fact that an increase in the number of previous CS increases the risk for placenta accrete by about 18 to 110 fold. 4

\section{Limitations}

In our study there was small number of patients. There was no direct established relationship between $\mathrm{PPH}$ and demographic variables like age, parity number of antenatal visits etc. due to the retrospective nature of the study. The time taken to complete the operative procedure (Total or Subtotal hysterectomy) could not be assessed from this study.

\section{CONCLUSIONS}

In our study, the incidence of EPH is similar to the reported incidence in literature. The main indication of EPH was atonic $\mathrm{PPH}$, which is associated with multiparity in most of the cases. The second most common indication is uterine rupture associated with either injudicious use of oxytocics/ misoprostol (outside) in multiparous women or previous $\mathrm{h} / \mathrm{o}$ caesarean section. Indications for EPH have been changing now. Now-a-days, abnormal placentation is the major indication of EPH rather than uterine atony and rupture uterus. This is due to proper labour management, early management of atonic PPH with uterotonic agents, and increasing tendency towards CS which predisposes to abnormal placentation. Hence the risk factors associated with EPH are multiparity, previous h/o caesarean section, inadequate antenatal care and improper education to the women in our society. So, the incidence of EPH can be reduced in our institution by improving socioeconomic status, upgradation of the educational level of women, counseling for adequate antenatal care, promotion and upgradation of health care facilities especially in lower tier level, proper monitoring of labour with use of partograph, cardiotocography (CTG), judicious use of oxytocics/ misoprostol, reducing rate of primary caesarean section, early referral to tertiary care centres and adoption of small family norm using proper motivation as well as counseling to the patients.

\section{ACKNOWLEDGEMENT}

We would like to thank Dr. (Prof.) Partha Mukherjee, Head of The Department (Gynaecology \& Obstetrics), Medical College Hospital, Kolkata for planning and supporting our study. We would also like to thank to Dr. Suchibrata Das, Assistant Prof. (Dermatology), NRS Medical College for helping in the preparation of study materials. We would also likely to thank Dr. Amit Kyal, Associate Prof. (Gynaecology \& Obstetrics), Medical College Hospital, Kolkata for advising and proper presentation of study materials. Dr. Rituraj and Dr. Adwaita Pandit, two M.S. PGTs have helped us a lot. 


\section{REFERENCES}

[1] Park EH, Sachs BP. Postpartum haemorrhage and other problems of third stage. In: James DK, Steer PJ, Weiner $\mathrm{CP}$, et al. eds. High risk pregnancy - management options. $2^{\text {nd }}$ edn. Philadelphia, Pa, USA: W.B. Saunders Publications 1999: p. 1231-46.

[2] Jin R, Guo Y, Chen Y. Risk factors associated with emergency peripartum hysterectomy. Chin Med J (Engl) 2014;127(5):900-4.

[3] Hoblidar S, SunilKumar KS, Desai RM. Emergency peripartum hysterectomy: a retrospective study of 7 years. Int J Reprod Contracept Obstet Gynecol 2016;5(9):3112-5.

[4] Cintesun E, Cintesun FNI. Emergency peripartum hysterectomy in the Eastern Region of Turkey: incidence and maternal morbidity. International Journal of Anatomy, Radiology and Surgery 2018;7(1):0001-5.

[5] Gurtani FM, Fadaei B, Akbari M. Emergency peripartum hysterectomy in Isfahan: maternal mortality and morbidity rates among the women who underwent peripartum hysterectomy. Adv Biomed Res 2013;2:20.

[6] Machado LS. Emergency peripartum hysterectomy: Incidence, indications, risk factors and outcome. $\mathrm{N} \mathrm{Am} \mathrm{J}$ Med Sci 2011;3(8):358-61.

[7] Kwame-Aryee R, Kwakye A, Seffah J. Peripartum hysterectomies at the korle-bu teaching hospital: a review of 182 consecutive cases. Ghana Medical Journal 2007;41(3):133-8.

[8] Carvalho JF, Cubal A, Torres S, et al. Emergency peripartum hysterectomy: a 10-year review. Article ID 721918, International Scholarly Research Notices 2012;2012:1-7.
[9] Ozden S, Yildirim G, Basaran T, et al. Analysis of 59 cases of emergent peripartum hysterectomies during a 13year period. Archives of Gynaecology and Obstetrics 2005;271(4):363-7.

[10] Nasrat HA, Youssef MH, Marzoogi A, et al. "Near miss" obstetric morbidity in an inner city hospital in Saudi Arabia, mortality. East Meditarr Health J 1999;5(4):71726.

[11] Fatima M, Kasi PM, Baloch SN, et al. Experience of emergency peripartum hysterectomies in a tertiary care hospital in Quetta, Pakistan. Article ID 854202, International Scholarly Research Notices (ISRN) Obstetrics and Gynecology 2011;2011:1-4.

[12] Zamzami YTY. Indication of emergency peripartum hysterectomy: review of 17 cases. Archives of Gynecology and Obstetrics 2003;268(3):131-5.

[13] Bai SW, Lee HJ, Cho JS, et al. Peripartum hysterectomy and associated factors. Journal of Reproductive Medicine 2003;48(3):148-52.

[14] Singh A, Hada M, Yangzom K, et al. Emergency peripartum hysterectomy. Nepal J Obstet Gynaecol 2006;1(2):33-6.

[15] Obiechina NJ, Eleje GU, Ezebialu IU, et al. Emergency peripartum hysterectomy in Nnewi, Nigeria: a 10-year review. Nigerian Journal of Clinical Practice 2012;15(2):168-71.

[16] Abasiattai AM, Umoiyoho AJ, Utuk NM, et al. Emergency peripartum hysterectomy in a tertiary hospital in southern Nigeria. Pan African Medical Journal 2013;15:60.

[17] Stanco LM, Schrimmer DB, Paul RH, et al. Emergency peripartum hysterectomy and associated risk factors. Am J Obstet Gynecol 1993;168(3):879-83. 